\title{
A web-GIS for the choice of the path in regional greenways
}

\author{
G. Salvo \& B. Lo Casto \\ DITRA, Department of Transport Engineering, \\ University of Palermo, Italy
}

\begin{abstract}
Tourists seem less interested in the traditional sites of mass tourism, which has damaged local identities. The tourist reclaims the old function of journey, intent on widening his knowledge of the surrounding territory while respecting the social and cultural equality of other members of the population.

This study outlines a methodology to identify the generalized cost for a system of non-motorized transport in order to determine the modal choice of users and the route of minimum cost to reach the desired destination. Within the information users, a key role is played by telematics, which are now widely accessible through web interfaces. With the word greenways we mean the network for the non-motorized, constituted by paths inserted in a natural context with particular attention to the historic and cultural patrimony of the territory.

The trend of research in the field of greenways today is strongly geared towards the infrastructural design of routes. The specific studies and manuals, such as the Dutch CROW, reported mainly geometric patterns of infrastructure and design criteria for parking areas, to improve the transit of pedestrians and bicycles. From the user's perspective it becomes relevant to bring this to fruition because of its main attributes: physical effort and safety, especially for nonsystematic users who may have knowledge about places but not on the tracks and their level of difficulty. In this sense, the greenways are designed both as continuous long-distance routes and as local networks suitable for systematic trips.
\end{abstract}

The GIS contains layers and topological mapping with tourist and local information and a network of greenways, composed of individual links with a weight corresponding to the generalized cost needed to pass, which coincides with the physical demands of the user. This effort coincides with the energy to 
spend to overcome all the resistance to motion characteristics of the link. The study compares the energy expressions derived from physics and kinematics with expressions of experimental nature, to obtain the expression of power required to pass through the link, indicating the degree of difficulty of the route. The user, through the ability to overlay topology, the ease of updating data provided by the GIS and the usability of the information from the web, can plan their journey across the network in response to the level of difficulty related to their physical conditions, the presence of services necessary for the trip and the natural, historical and cultural interest.

Information regarding the presence of other transport (bus, rail and private transport) networks for access/egress of the network of greenways and the corresponding service (times, frequency, interchange points) is provided.

The design of the network of greenways may contain, in addition, links for the exclusive use roads characterized by low emission and low speed in order to increase the capillary network.

The study is proposed as a further advancement for the determination of an estimation model from the user in the rate of generalized cost on the perception of traffic safety related to the situation of affinity with motorized traffic.

Keywords: tourist development, greenways, telematics.

\section{Introduction}

A greenways network is a network for non-motorized mobility consisting of paths, inserted in natural areas with particular attention to the historical and cultural heritage, characterized by a high level of service [1].

The trend of research in the field of greenways, today, is strongly directed towards defining the design criteria of network of routes that are:

- useful, to satisfy the current travel needs and propose new routes;

- $\quad s a f e$, with particular attention to vulnerable users;

- pleasant, to make moving a pleasant experience.

Studies and manuals, such as the Dutch CROW [9], reported mainly geometric patterns of infrastructure and design criteria for parking areas, to improve the transit of pedestrians and bicycles. Relevant to users is the use of greenways with their main attributes: physical effort and safety [3-5].

All this is especially true for users who may have knowledge about places but not on the tracks and their level of difficulty. In this sense, the greenways are designed both as a continuous long-distance route and as a local network suitable for systematic trips.

The greenways are designed for a "slow" fruition, where physical training or special equipment are not required.

This study outlines a methodology to identify the generalized cost for a system of non-motorized transport in order to determine the modal choice of users and the route of minimum cost to reach the desired destination. Within the 
information users, a key role is played by telematics now widely accessible through web interfaces.

\section{Methodology to identify the cost of links}

The designer of a network of trails devoted to non-motorized mobility must have a thorough knowledge of the technical limitations and performance of both the means (bicycle, scooter) with the user (cyclist, pedestrian, etc.) [4], [6-8].

Research has focused attention on a particular category of users: cyclists. The reason for this choice is dictated by the increasing development of cycling tourism in recent years and the subsequent attention that these users put in the prior definition of the itinerary.

In fact the user is both a driver and supplier of power necessary for motion [7]. The power that a cyclist can generate is limited and tends to vary depending on the resistance encountered during the motion and in relation to his physical abilities.

In order to determine a standard type of cyclist, we have considered a man aged between 50 and 60 years. This type of user is capable of providing a power (P) of about 85 watts to overcome a route length of $2,000 \mathrm{~m}$ on the flat and on a paved path. This value may reach a peak value of about 150 watts in the first minutes of motion (for a woman these values are reduced by approximately $20 \%$ ) [10].

The power delivered by the rider depends on his physical abilities, the value of commercial speed desired and the reason for travel. The values of power output are generally more stable in the case of travel for recreational purposes.

That power is expended by the cyclist to win all the resistance that occurs during the motion.

These resistances are divided into ordinary and accidental resistances:

- ordinary resistances are opposed to progress of the vehicle in motion straight and on the flat (aerodynamic resistance, resistance to mechanical transmission components, rolling resistance);

- accidental resistances, occurring in the presence of an inclination (slope resistance) and during the motion of the vehicle in curves (resistance in curve).

In relation to the type of transport and the low speeds $(10-20 \mathrm{~km} / \mathrm{h})$, we considered irrelevant some resistances as the rolling resistance, frictional resistance and the resistance accidental in curve.

In literature there are many expressions of power as a function of different physical and environmental parameters. Among these, the formula suggested in the manual Dutch CROW [9], for the design of cycling facilities, is more generally applicable. In this expression the power $\mathrm{P}$, required to pass a link with the inclination $i$, maintaining a constant speed, is: 


$$
\mathrm{P}=\left(0.0981 \cdot i \cdot m+0.0721 \cdot m+0.374 \cdot v^{2}\right) \cdot v
$$

where:

$$
\begin{array}{ll}
\mathrm{P} & =\text { power required to maintain constant speed } v \\
i & =\text { inclination } \\
m & =\text { total mass of the cyclist and of the bike } \\
v & =\text { desired speed }
\end{array}
$$

Defining:

$\mathrm{Ls}=$ the work corresponding to the maximum effort to overcome a path of 2000 $\mathrm{m}$ on the flat;

$\mathrm{L}=$ the work needed to overcome a link $l$, with inclination $i$ the difficulty index is defined as:

$$
\begin{gathered}
I=\frac{L}{L_{s}} \\
L_{s}=P \cdot l \quad(\mathrm{watt} \cdot \mathrm{m}) \\
L=P_{s} \cdot 2000 \quad(\text { watt } \cdot \mathrm{m})
\end{gathered}
$$

This index helps to value the degree of difficulty that each link requires to be crossed in relation to the user's physical ability and performance.

- If $\mathrm{I}<1$, the link can be overcome by the power available, without interruption;

- If $\mathrm{I}=1$ is the limiting case where all the power generated is spent to overcome the link;

- If $\mathrm{I}>1$, the link cannot be overcome, and the cyclist must reduce his speed or stop the time needed for physical recovery.

Assigning a value of speed $v$ at each link of the network, we can determine the degree of difficulty $I j$ of each link $j$.

The calculation of the difficulty to associate the entire itinerary is not the result of algebraic summation of the individual indices $I j$, because the cyclist suffers from the efforts to traverse the links above. Past the link $j$, the residual power $P r$, which can be spent to overcome the next link and so on, must be calculated.

Repeating this process for the entire route, we will determine the effort that the user has to pay to complete his travel and estimate the time for physical recovery or any stops. 


\section{An application in Sicily}

An application was made on an existing route network of greenways incorporated in the Sicilian greenways network: Bonagia - Macari [2].

This route has the important role of connecting the two paths on the north west coast of Sicily: the greenway Trapani - Custonaci and Castelluzzo - San Vito Lo Capo. The route develops along the coast from the tuna processing factory of Bonagia until Macari.

\subsection{Use of GIS}

The first step is the relief of the Greenway, where all the links forming the entire path are plotted, distinguishing them by: type (path, cycle track, pedestrian street), surface (paved and not paved floor), dangerous part (not protected road or rail crossings are, part of the path displayed on cliffs or similar), state of maintenance, accessibility for the different categories of cyclists (trained and non-trained adults, children, handicapped, elderly, etc..), lane (own or mixed).

During the relevant territorial some information, concerning the aspects related to environmental and local tourism, the presence of other transport systems, and the characteristics of exercise (stops, times, frequency, availability of parking areas, etc.), are collected.

Items of interest found were classified into the following categories:

- Elements of natural (areas covered by vegetation of particular value, viewpoints, parks and gardens, etc.);

- Elements of architectural and historical interest (housing zones, archaeological sites, theatres, streets, museums, mills, furnaces, etc.).

The analysis phase has allowed the collection of a considerable amount of information that was subsequently shown on the map. The map scale is $1: 10,000$ for the region and proved the perfect solution for mid-level studies, and 1:2000 for the analysis of smaller areas that are particularly rich in elements to be mapped. This choice was dictated by the need for accurate information and ability to be easily read.

The information collected was incorporated into a GIS. It is a tool that can manage many geo-referenced spatial data, heterogeneous between them, drafting in order to get information, both alphanumeric and visual (photos, movies, etc.) and can provide a simple management and a quick update of spatial data input.

The implementation of GIS has allowed, at this early stage, to produce some thematic maps useful to identify the network of paths, to link the paths and the resources of the territory and to represent the same paths divided according to their degree of difficulties. Within the GIS some basic thematic elements were also places (administrative boundaries, hydrography, roads network, etc.) necessary for understanding the essential elements of the territory.

For the purpose of the project elements used are the regional technical maps of Sicily, the landscape plan of the Sicilian Region, several literature sources to 
characterize the historical monuments in the area, and the GIS software ArcView.

\subsection{The route}

The route, on which we wanted to test the methodology developed starts from the district of Bonagia, now restored and converted into a large tourist resort with an hotel, restaurant, pool, beaches, sports facilities and craft shops. In the tower, also restored, the Museum of tuna processing factory can be visited, evidence of ancient seafaring activities.

After leaving the district, the route takes the path that runs along the coast towards the Natural Reserve of Mount Cofano. This mountain is characterized by a Mediterranean vegetation of broom, carob trees and dwarf palms. On the summit there is an old watchtower from where the beautiful panorama of the Gulf of Bonagia can be admired.

Table 1: Characteristics of the route Bonagia - Mount Cofano - Macari.

\begin{tabular}{|c|c|c|c|c|c|}
\hline PATH & $\begin{array}{c}\text { Altitude } \\
(\mathrm{m})\end{array}$ & $\begin{array}{c}\text { Length } \\
(\mathrm{km})\end{array}$ & $\begin{array}{c}\text { distance } \\
\text { gradually }(\mathrm{km})\end{array}$ & $\begin{array}{c}\text { Slope } \\
(\%)\end{array}$ & $\begin{array}{c}\text { Type of } \\
\text { surface }\end{array}$ \\
\hline Bonagia & 5.50 & 5.500 & 0 & & \\
\hline Ponte Forgia & 41.00 & 6.500 & 6.500 & +0.55 & dirt road \\
\hline Bivio Contrada Comino & 9.90 & 2.900 & 9.400 & -1.07 & dirt road \\
\hline Crocifisso Monte Cofano & 53.00 & 1.900 & 11.300 & +2.27 & dirt road \\
\hline Punta del Saraceno & 8.60 & 0.700 & 12.000 & -6.34 & dirt road \\
\hline Seno dell'Arena & 2.80 & 6.200 & 18.200 & -0.09 & dirt road \\
\hline SP 16 località Macari & 24.10 & 0.600 & 18.800 & +3.55 & dirt road \\
\hline
\end{tabular}

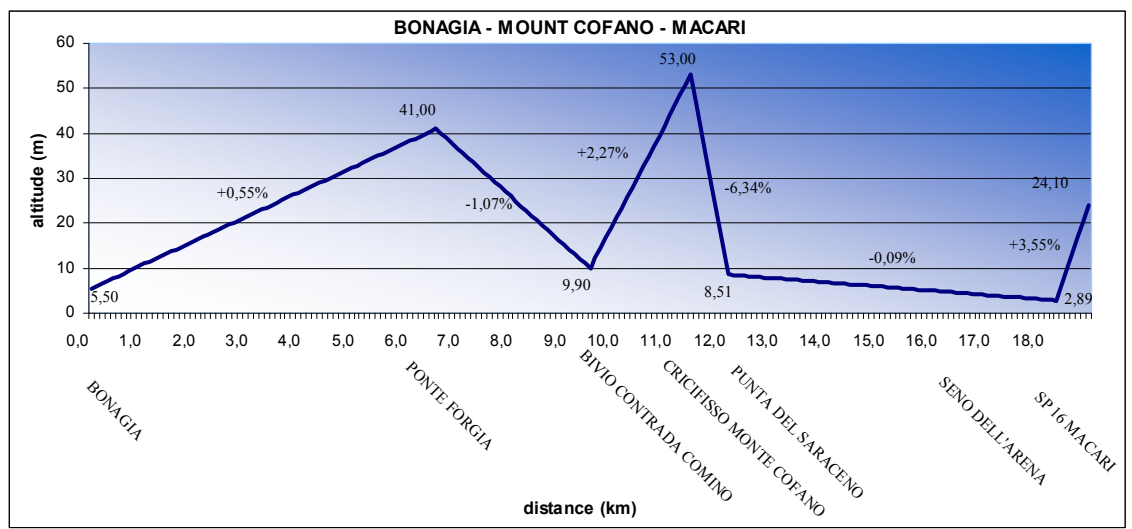

Figure 1: Height profile of the route Bonagia - Mount Cofano - Macari. 


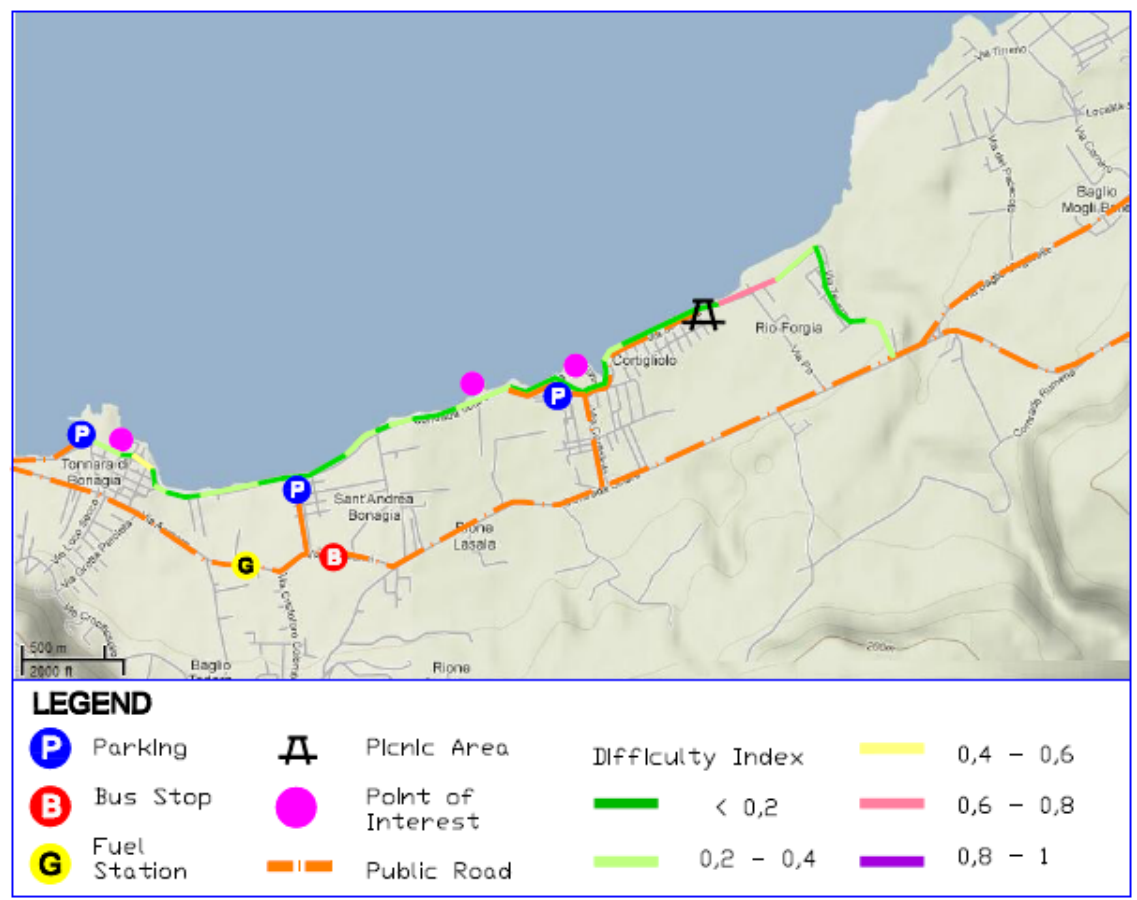

Figure 2: $\quad$ Planimetry of the route Bonagia - Mount Cofano - Macari.

The Nature Reserve is located in the territory of Custonaci and includes the area of the promontory of Mount Cofano, natural oasis, crossed by the Greenway, which runs along the jagged coast of the sea. On the slopes of the mountain there are some towers of the Spanish era, the remains of a tuna processing factory, and several caves, including those Scurati, Mangiapane and Miceli that can be reached by the route "Bonagia - Custonaci".

After passing the promontory of Mount Cofano the route continues along the path of cost up to graft in the itinerary "Castelluzzo - San Vito Lo Capo" near the cliffs of Macari. Table 1 shows the characteristics of the route.

\section{The web interface}

The Internet allows a global spread of news about the path to be promoted. The information was included in an existing site accessible through some specialized sites involved in cycle-tourism and some sites operated by local governments involved in the management of greenways and in promoting ecotourism of its territory.

The website was organized as a series of informative pages as printed publications, which provide the information requested from users.

All the information (technical information on the route, photographs, touristic information, cultural information, information on the physical effort to support), 
structured within a Geographical Information System, allow the user to query the database to obtain specific information and personalized maps.

Furthermore, as described above, the innovative service for the evaluation of the power needed to overcome a link is provided through the web. Particularly through the web the user can evaluate the power necessary to overcome, with a chosen speed, a link of the network.

The user initially selects the route and sets a driving speed in relation to his performance characteristics, and subsequently obtains by the website the index of difficulty. Through this index, the user can estimate the degree of effort required to overcome each link of the path and the route as a whole, according to his physical abilities.

Some fundamental information on other transport systems, public (railway stations, bus stops for public transport, timetable, frequency, etc.) and private (primary and secondary roads, parking, etc.) are included in the web.

The management of all this information through a web-GIS allows the user to plan a personalized itinerary, also with the possibility to use other transport systems for realize an intermodal transport.

\section{References}

[1] Toccolini, A., Fumagalli, N., Senes, G., 2004. Progettare i percorsi verdi. Manuale per la realizzazione delle Greenways. Maggioli Editore, Rimini.

[2] Dipartimento Trasporti e Comunicazione, Regione Siciliana. 2004. Studio per la realizzazione di una rete di percorsi verdi dedicata alla mobilità non motorizzata in Sicilia.

[3] European Greenways Association, 2000. The European Greenways Good Practise Guide. Ibergraficas, Madrid.

[4] Aashto, 1999. Guide for the development of bicycle facilities. Washington D.C. (USA).

[5] Fundacion de los Ferrocarriles Españoles, 1998. Guia de Vias Verdes. Josmar, España.

[6] Antonakos, C. L., 1994. Environmental and Travel Preferences of cyclist. Transportation Research Record 1438, pp. 25-32.

[7] Pratelli, A., 1998. Una metodologia per progettare una rete di percorsi ciclabili. Trasporti e Trazione, $\mathrm{n}^{\circ}$ 1, pp. 15-24.

[8] Flink, C.A, 1993. Greenways. A guide to planning, design and development. Island Press, Washington D.C. (USA).

[9] C.R.O.W., 1993. Sign up for the bike - Design manual for a cycle-friendly infrastructure. Record 10, C.R.O.W., The Netherlands.

[10] Dirken, J.M. 1978 Functional age of industrial workers. Noordhoff, Groningen. 